\title{
, nax \\ Numerical Analysis of Wick-Type Two-Phase Mechanically \\ Pumped Fluid Loop for Thermal Control of Electric Aircraft Motors
}

\author{
Xinyu Chang *, Koji Fujita (D) and Hiroki Nagai (D) \\ Institute of Fluid Science, Tohoku University, Sendai 9808577, Japan; fujita.koji@tohoku.ac.jp (K.F.); \\ nagai.hiroki@tohoku.ac.jp (H.N.) \\ * Correspondence: xinyu.chang.c3@tohoku.ac.jp; Tel.: +81-22-217-5326
}

check for updates

Citation: Chang, X.; Fujita, K.; Nagai, H. Numerical Analysis of Wick-Type Two-Phase Mechanically Pumped Fluid Loop for Thermal Control of Electric Aircraft Motors. Energies 2022, 15, 1800. https://doi.org/ $10.3390 /$ en15051800

Academic Editor: Silvio Simani

Received: 31 January 2022

Accepted: 24 February 2022

Published: 28 February 2022

Publisher's Note: MDPI stays neutral with regard to jurisdictional claims in published maps and institutional affiliations.

Copyright: (C) 2022 by the authors. Licensee MDPI, Basel, Switzerland. This article is an open access article distributed under the terms and conditions of the Creative Commons Attribution (CC BY) license (https:// creativecommons.org/licenses/by/ $4.0 /)$.

\begin{abstract}
The development of thermal control systems has become an important issue in nextgeneration electric aircraft design due to the increase in heat exhausted with electrification. In this paper, a wick-type two-phase mechanically pumped fluid loop system for future electric aircraft was proposed through the investigation of current two-phase flow cooling technology. Taking the experimental electric aircraft X-57 as an example, a wick-type two-phase mechanically pumped fluid loop with four evaporators for transporting $12 \mathrm{~kW}$ of waste heat within an $80{ }^{\circ} \mathrm{C}$ temperature limit was proposed and its feasibility was confirmed. A numerical model was constructed and validated to predict the operating characteristics of a two-phase mechanically pumped fluid loop. The optimal pump outputs under-even and uneven heat load conditions and was investigated for the first time by considering the vapor-liquid separation conditions in each flow path and the power consumption of the pump. Under the optimal pump output condition, the operating characteristics of the wick-type two-phase mechanically pumped fluid loop system were calculated. The calculation results indicate that the proposed wick-type two-phase mechanically pumped fluid loop is suitable as the thermal control system for an X-57 electric aircraft motor, as the calculation results satisfied the operational requirements of the motor.
\end{abstract}

Keywords: electric aircraft cooling devices; numerical model; mechanically pumped fluid loop

\section{Introduction}

Recently, the electrification of next-generation aircraft has become more important due to the need to reduce the emission of carbon dioxide. Several small electric aircraft have been proposed, and a flight experiment has also been conducted [1-4]. Based on the knowledge obtained from small electric aircraft, a large passenger aircraft was proposed [5-8], and the application was planned to commence before 2035 to meet the requirements of the International Air Transport Association (IATA) roadmap [9]. However, with electrification, the heat generation density of the battery, electric motors, and avionics is expected to increase rapidly due to the miniaturization of the aircraft body. As a result, it is difficult for the existing air-cooling method to exhaust all the waste heat to the surroundings. Currently, due to the temperature limit, the flight period of an experimental electric aircraft is confined to approximately one hour. Therefore, advanced thermal control systems for electrification aircraft are required [10-14].

A similar thermal management issue also exists in satellites and spacecraft. A robust, capillary-pumped, two-phase heat transfer loop heat pipe (LHP) was proposed for cooling the electronic components installed in satellites and spacecraft. This LHP does not require electric power and features a large heat transfer distance, high heat transfer capacity, and flexible configuration $[15,16]$. In addition, the ground uses of LHPs for cooling engines and central processing units (CPU) have been proposed [17-19]. However, it is difficult for 
the LHP to cool intense heat sources, such as the electric aircraft's motor, as a result of the insufficient driving force. To solve this problem, an additional driving force is required.

Instead of the capillary pump, a mechanical pump can be employed to cool components with high heat generation, owing to its effectiveness in other applications. A single-phase, mechanically pumped fluid loop was used as the heat transfer device in the Mars rover, Curiosity, to cool the waste heat from a radioisotope thermoelectric generator (nuclear battery) [20]. The two-phase, mechanically pumped fluid loop (2PMPFL) was proposed as a future heat transfer device owing to the following characteristics: (1) better heat transfer performance compared to single-phase flow; and (2) lower power consumption due to the low mass flow rate in the 2PMPFL.

Two types of 2PMPFLs were mentioned by Daimaru, T. et al. [21]. The first is the wickless-type 2PMPFL, which uses a mechanical pump to circulate the working fluid. Existing research on wickless-type 2PMPFLs includes studies conducted on the ground and on the Kibo module of the international space station, to investigate the two-phase flow boiling phenomena in the evaporator [22-28]. In the wickless-type 2PMPFL, the two-phase flow boiling behavior in the evaporator is difficult to predict, given the lack of vapor-liquid separation. Poor flow stability results in an uneven temperature distribution in the evaporator surface. A more reliable 2PMPFL system is necessary due to an even temperature distribution across the evaporator is desired.

The second type of 2PMPFL, mentioned by Daimaru, T. et al. [21], is the wick-type 2PMPFL. In this type, a porous structure called wick is employed in the evaporator to achieve vapor-liquid separation. Compared to the wickless-type 2PMPFL, the wick-type 2PMPFL offers the following advantages. (1) The wick enables vapor-liquid separation in the evaporator, which enhances flow stability, especially in the wick-type 2PMPFL system including multiple evaporators. As a result, the operating characteristics are easier to predict. (2) The wick forms a uniform vapor-liquid boundary, creating an even temperature distribution in the evaporator. (3) The wick can provide additional capillary pump capability, alongside the mechanical pump capability, which improves the operating performance of the wick-type 2PMPFL.

Several experimental approaches have been conducted to investigate the heat transfer performance of wick-type 2PMPFLs with one evaporator [29-35], two evaporators [36,37], and six evaporators [38]. However, a detailed design method and numerical model for the wick-type 2PMPFL was not established as a result of the complicated operating behavior.

In this paper, a wick-type 2PMPFL with multiple evaporators was proposed as the potential thermal control system for cooling multiple heat sources in future electric aircraft. Firstly, a one-dimensional steady-state numerical model for the proposed wick-type 2PMPFL cooling system with four evaporators was established to confirm whether it satisfies the thermal control requirements of the electric aircraft motor. The four heat sources (generator, converter, inverter, and rotor) in the motor were assumed to be cooled through four evaporators, and the surface of the wing was assumed to be the heat dissipation area. In the numerical model, for the first time, the optimal output condition of the pump (i.e., the optimal pump capacity) was deduced by considering the vapor-liquid separation in each flow path and the power consumption. Under the optimal conditions of the pump, the following attributes were investigated; the operating temperature of the evaporators and accumulators, and the mass flow rate in each flow path.

\section{Wick-Type Two-Phase Mechanically Pumped Fluid loop}

\subsection{Operating Characteristics}

Figure 1 presents an image of the proposed wick-type 2PMPFL thermal management system with four evaporators. The wick-type 2PMPFL absorbs waste heat from the powered machine and transfers the waste heat to a cold surrounding on the condenser side through the phase change of the inner working fluid (i.e., vapor to liquid). A mechanical pump is used to circulate the working fluid, which efficiently transports heat from the evaporator to the condenser. 


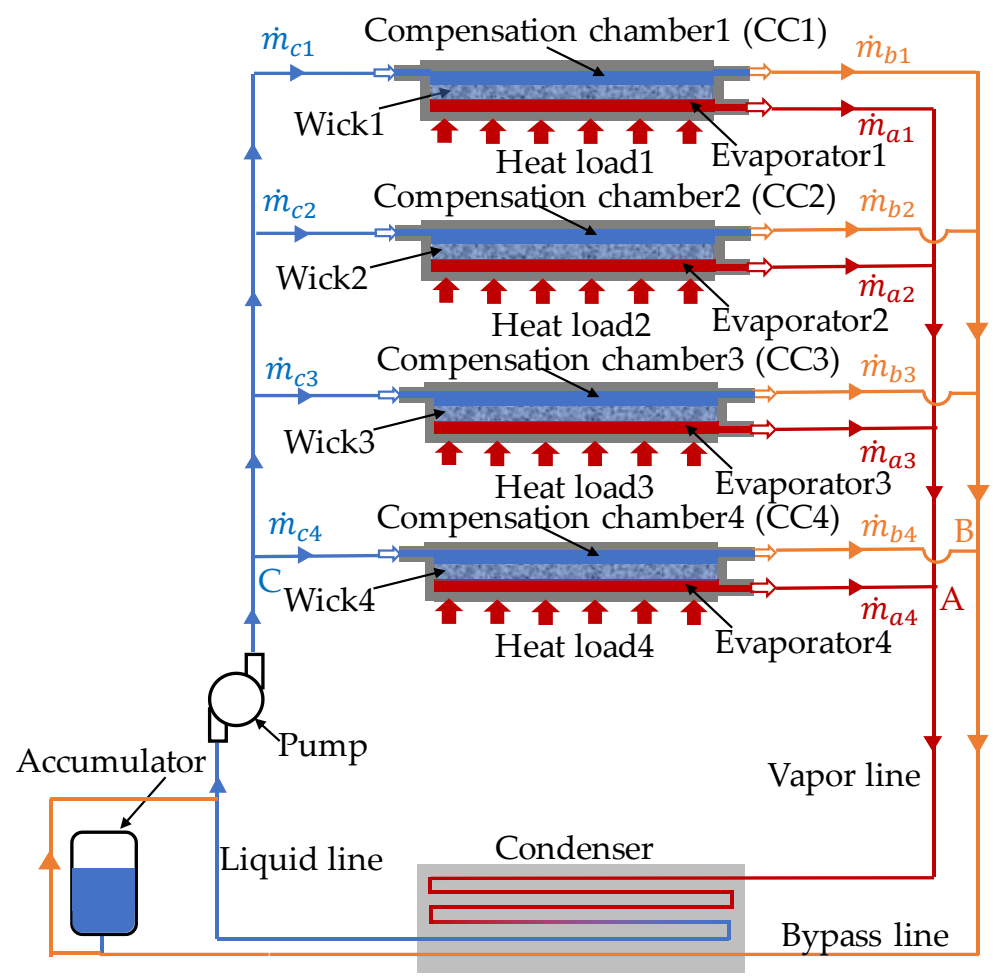

Figure 1. Schematic of a wick-type 2PMPFL with four evaporators (not to scale).

Evaporators with isothermal temperature variations were developed in the authors' previous research [39-41]. A porous structure, called a wick, is presented in each evaporator. As a uniform vapor-liquid boundary can be generated in the wick, the temperature variation in the evaporating surface is small. As a result, the heat source can be cooled with an even temperature distribution heat transfer surface. Furthermore, the wick also contributes toward the flow stability of the working fluid in the evaporators by separating the vapor and liquid flows; this makes predicting the operating characteristics of the 2PMPFL less complicated.

There are two flow paths in the wick-type 2PMPFL. One is the main flow path, where the working fluid flows from the liquid line's divergence point $C$ through the primary wick in each evaporator, the vapor line junction point $A$, the condenser, and then returns to point $\mathrm{C}$. The other is the bypass flow path, where the working fluid flows from the liquid line's divergence point $C$ through each compensation chamber (CC), the bypass line junction point $B$, and then returns to point $C$. An accumulator was installed near the mechanical pump to regulate the amount of working fluid in the fluid loop when the heat load varies.

During the operation of the wick-type 2PMPFL, the mass flow rate throughout the wicktype 2PMPFL is controlled by the mechanical pump. In the main flow path, the mass flow rate can be estimated using heat loads. After calculating the mass flow throughout the wick-type 2PMPFL and the main flow path, the mass flow rate in the bypass line can be calculated.

\subsection{Design Method}

In this work, as the first step, a wick-type 2PMPFL was proposed to realize the thermal control of the Maxwell X-57 aircraft's cruise motor, which was developed by the ESAero corporation in 2017 [42]. As the existing thermal control system is incomplete and the steady-state temperature is beyond the operating temperature limit, the current flight period of the X-57 is limited to one hour before the temperature exceeded the operating limit.

The power of the X-57 cruise motor is $60 \mathrm{~kW}$, and the efficiency is assumed to be $80 \%$, considering the design margin. Therefore, supposing all the losses are transformed to heat, the amount of heat generated is $12 \mathrm{~kW}$. The heat generation system consists of four components: a generator, converter, inverter, and rotor. The maximum amount of heat generated by each component was estimated to be $3 \mathrm{~kW}$. A part of the wing area 
$(0.53 \mathrm{~m} \times 3 \mathrm{~m})$ at the top and bottom surfaces was used as the heat-dissipating surface. During the flight period, the air temperature was assumed to be $20{ }^{\circ} \mathrm{C}$, and the flight speed was $76.9 \mathrm{~m} / \mathrm{s}$. The temperature limit of the cruise motor was set to $100{ }^{\circ} \mathrm{C}$. Considering the design margin, the temperature limit of the evaporator was set to $80^{\circ} \mathrm{C}$.

Table 1 shows the configurations of the wick-type 2PMPFL based on Figure 1, where a $12.7 \mathrm{~mm}$ tube was used as the vapor line and the condensing line with an inner diameter of $10.9 \mathrm{~mm}$, whereas a $6.35 \mathrm{~mm}$ tube was used as the liquid line with an inner diameter of $4.6 \mathrm{~mm}$. The length of the condensing line in the main flow path/bypass flow path was $12.1 \mathrm{~m} / 2.3 \mathrm{~m}$. The length of the liquid line in the main flow path and bypass flow path was $1.83 \mathrm{~m} / 1.5 \mathrm{~m}$. The volume of the accumulator was $2.55 \mathrm{~L}$. R245fa was selected as the working fluid considering its desirable properties: high critical temperature; a low global warming potential (more environmentally friendly); and excellent thermal and chemical stability. The charging amount was calculated to be $4.058 \mathrm{~kg}$ by considering the vapor-liquid distribution.

Table 1. Configuration of wick-type 2PMPFL.

\begin{tabular}{|c|c|c|c|}
\hline \multicolumn{2}{|c|}{ Evaporator } & \multicolumn{2}{|c|}{ Vapor Line } \\
\hline Length [mm] & 210 & Length $[\mathrm{m}]$ & 0.6 \\
\hline Width $[\mathrm{mm}]$ & 204 & Inner Diameter [mm] & 10.9 \\
\hline Thickness [mm] & 30 & \multicolumn{2}{|c|}{ Condenser line/ Bypass condenser line } \\
\hline \multicolumn{2}{|c|}{ Compensation chamber (CC) } & Length $[\mathrm{m}]$ & $12.1 / 2.3$ \\
\hline Length [mm] & 200 & Inner diameter $[\mathrm{mm}]$ & 10.9 \\
\hline Width $[\mathrm{mm}]$ & 200 & \multicolumn{2}{|c|}{ Liquid line/ Bypass liquid line } \\
\hline Thickness [mm] & 23.5 & Length $[\mathrm{m}]$ & $1.83 / 1.5$ \\
\hline \multicolumn{2}{|c|}{ Wick } & Inner diameter $[\mathrm{mm}]$ & 4.6 \\
\hline Length [mm] & 200 & \multirow{3}{*}{\multicolumn{2}{|c|}{$\begin{array}{l}\text { Accumulator volume: } 2.55 \mathrm{~L} \\
\text { Working fluid: R245fa } \\
\text { Charge amount: } 4.058 \mathrm{~kg}\end{array}$}} \\
\hline Width $[\mathrm{mm}]$ & 200 & & \\
\hline Thickness [mm] & 3 & & \\
\hline
\end{tabular}

\section{Numerical Model}

\subsection{Modeling System}

The mathematical model was established by referring to the LHP numerical model [43]. For the wick-type 2PMPFL, zero-dimensional numerical models were used for the evaporator and CC accumulator, and one-dimensional models were used for the vapor line, condenser line, liquid line, and bypass line to predict the temperature and pressure of each component.

Equations (1) and (2) show the energy balance conditions in each evaporator. $\mathrm{T}_{\text {evap }}$ and $\mathrm{T}_{\mathrm{ev}}$ represent the temperatures of the heating surface and the evaporating surface in wick, respectively.

$$
\mathrm{Q}_{\text {load }}=\mathrm{Q}_{\text {evap_amb }}+\mathrm{G}_{\text {evap_ev }}\left(\mathrm{T}_{\text {evap }}-\mathrm{T}_{\mathrm{ev}}\right)
$$

where $Q_{\text {load }}$ is the total heat load, $Q_{\text {evap_amb }}$ is heat lost to the surroundings, and $\mathrm{G}_{\text {evap_ev }}\left(\mathrm{T}_{\text {evap }}-\mathrm{T}_{\mathrm{ev}}\right)$ is the heat transferred to the wick's evaporating surface.

$$
\mathrm{G}_{\text {evap_ev }}\left(\mathrm{T}_{\text {evap }}-\mathrm{T}_{\mathrm{ev}}\right)=\dot{\mathrm{m}} \lambda+\mathrm{G}_{\text {wick }}\left(\mathrm{T}_{\mathrm{ev}}-\mathrm{T}_{\mathrm{cc}}\right)
$$

where $G_{\text {wick }}\left(T_{e v}-T_{c c}\right)$ is the heat lost to the CC side, and $\dot{m} \lambda$ is the heat absorbed through evaporation of the working fluid. 
Equations (3) and (4) represent the thermal conductance of the wick. $d_{\text {wick }}$ and $A_{\text {wick }}$ represent the thickness of the wick and the cross-sectional area of the wick, respectively.

$$
\begin{aligned}
& G_{\text {wick }}=\frac{\dot{\mathrm{m}} \mathrm{C}_{\mathrm{p}}}{\mathrm{e}^{\eta}-1} \\
& \eta=\frac{\dot{\mathrm{m}} \mathrm{C}_{\mathrm{p}} \mathrm{d}_{\text {wick }}}{\mathrm{k}_{\text {wick }} \mathrm{A}_{\text {wick }}}
\end{aligned}
$$

Equation (5) shows the energy balance condition in each CC. $Q_{\mathrm{cc} \_a m b}$ represents the heat leak from the $\mathrm{CC}$ to the surroundings, and $\mathrm{T}_{11 \_ \text {out }}$ is the liquid line outlet temperature.

$$
\mathrm{G}_{\text {wick }}\left(\mathrm{T}_{\mathrm{ev}}-\mathrm{T}_{\mathrm{cc}}\right)-\mathrm{Q}_{\mathrm{cc} \_ \text {amb }}=\dot{\mathrm{m}} \mathrm{C}_{\mathrm{p}}\left(\mathrm{T}_{\mathrm{cc}}-\mathrm{T}_{\text {ll_out }}\right)
$$

The temperature variation and pressure variation in the vapor, condenser, liquid, and bypass line were calculated using Equations (6) and (7), respectively. $T_{f}$ and $T_{a}$ represent the working fluid's temperature and the temperature of the surroundings, respectively; $\mathrm{G}_{\mathrm{f}_{-} \mathrm{a}}$ represents the thermal conductance between the working fluid and the surroundings.

$$
\begin{gathered}
\frac{d P}{d L}=f \frac{\rho u^{2}}{2} \frac{4}{d_{i n}} \\
\frac{d T}{d L}=\frac{G_{f \_a}\left(T_{f}-T_{a}\right)}{\dot{m} C_{p}}
\end{gathered}
$$

Müller-Steinhagen and Heck's equations (Equations (8) and (9)) were used to calculate the pressure drop in the two-phase flow region, and Fujii's equation (Equations (10)-(17)) was used to calculate the Nusselt number over the inner surface of the condensing tube in the two-phase flow region $[44,45]$.

$$
\begin{aligned}
& \left(\frac{d P}{d L}\right)_{f, 2 p h}=G x(1-x)^{\frac{1}{3}}+\left(\frac{d P}{d L}\right)_{f, v} x^{3} \\
& \mathrm{G}=\left(\frac{\mathrm{dP}}{\mathrm{dL}}\right)_{\mathrm{f}, \mathrm{l}}+2\left[\left(\frac{\mathrm{dP}}{\mathrm{dL}}\right)_{\mathrm{f}, \mathrm{V}}+\left(\frac{\mathrm{dP}}{\mathrm{dL}}\right)_{\mathrm{f}, \mathrm{l}}\right] \\
& \mathrm{Nu}_{\mathrm{F}}=0.018 \operatorname{Re}_{\mathrm{L}}^{0.9}\left(\frac{\rho_{\mathrm{l}}}{\rho_{\mathrm{v}}}\right)^{0.45}\left(\frac{\mathrm{x}}{1-\mathrm{x}}\right)^{0.1 \mathrm{x}+0.8}\left(\operatorname{Pr}_{\mathrm{L}}+\frac{8000}{\operatorname{Re}_{\mathrm{L}}^{1.5}}\right)^{\frac{1}{3}}\left(1+\mathrm{C}_{\mathrm{F}} \mathrm{H}_{\mathrm{L}}\right) \\
& C_{\mathrm{F}}=0.071 \operatorname{Re}_{\mathrm{L}}^{0.1}\left(\frac{\rho_{\mathrm{l}}}{\rho_{\mathrm{v}}}\right)^{0.55}\left(\frac{\mathrm{x}}{1+\mathrm{x}}\right)^{0.2-0.1 \mathrm{x}}\left(\operatorname{Pr}_{\mathrm{L}}+\frac{8000}{\operatorname{Re}_{\mathrm{L}}^{1.5}}\right)^{\frac{1}{3}} \\
& \mathrm{H}_{\mathrm{L}}=\frac{\mathrm{k}_{\mathrm{l}}\left(\mathrm{T}_{\mathrm{f}}-\mathrm{T}_{\mathrm{W}}\right)}{\mu_{\mathrm{L}} \lambda} \\
& \mathrm{Nu}_{\mathrm{FG} \_\mathrm{G}}=0.725\left(\frac{\mathrm{Ga}_{\mathrm{D}}}{\mathrm{H}_{\mathrm{L}}}\right)^{\frac{1}{4}}\left(\frac{1+0.003 \mathrm{Pr}_{\mathrm{L}}^{\frac{1}{2}} \mathrm{C}_{\mathrm{FG}}^{3.1-\frac{0.5}{\mathrm{Pr}_{\mathrm{L}}}}}{1+\mathrm{C}_{\mathrm{FG} \_\mathrm{G}} \mathrm{C}_{\mathrm{G}}}\right)^{0.3} \\
& \mathrm{C}_{\mathrm{G}}=\left(1+1.6 \times 10^{11} \mathrm{H}_{\mathrm{L}}^{5}\right)^{0.25}\left(\frac{\rho_{\mathrm{v}}}{\rho_{\mathrm{L}}}\right)^{\frac{1}{2}}\left[\left(\frac{\mathrm{Ga}}{\mathrm{H}_{\mathrm{L}}}\right)^{\frac{1}{4}} \frac{\mathrm{d} \mu_{\mathrm{L}}}{\dot{\mathrm{m}}_{\mathrm{L}} \mathrm{X}}\right]^{1.8} \\
& \mathrm{C}_{\mathrm{FG}}=\frac{0.47 \mathrm{H}_{\mathrm{L}}^{\frac{1}{12}}\left(\frac{\rho_{\mathrm{V}}}{\rho_{\mathrm{L}}}\right)^{\frac{1}{2}}\left(\frac{\operatorname{Re}_{\mathrm{L}} \mathrm{x}}{1-\mathrm{x}}\right)^{0.9}}{\left(\frac{\mathrm{Ga}_{\mathrm{D}}}{\mathrm{H}_{\mathrm{L}}}\right)^{\frac{1.1}{4}}}
\end{aligned}
$$




$$
\begin{gathered}
\mathrm{C}_{\text {FG_G }}=20 \mathrm{e}^{-\frac{\dot{m}}{3000 \mathrm{~d} \mu_{\mathrm{L}}}} \\
\mathrm{Ga}_{\mathrm{D}}=\frac{\mathrm{gd}_{\mathrm{in}}^{3}}{v_{\mathrm{L}}^{2}}
\end{gathered}
$$

In Equations (8) and (9), $\left(\frac{d P}{d L}\right)_{f, 2 p h}$ represents the gradient of the two-phase flow pressure drop, $\left(\frac{d P}{d L}\right)_{f, v}$ represents the gradient of the pressure drop assuming that the entire working fluid is in the vapor phase, and $\left(\frac{d P}{d L}\right)_{f, l}$ represents the gradient of pressure drop assuming that the entire working fluid is in the liquid phase.

In Equations (10)-(17), $\mathrm{Nu}_{\mathrm{F}}$ is the Nusselt number in the forced convection condensation region, and $\mathrm{Nu}_{\mathrm{FG}_{\mathrm{G}}}$ is the Nusselt number from the co-existing forced and natural convection condensation region to the end of the natural convection condensation region. The larger value between $\mathrm{Nu}_{\mathrm{F}}$ and $\mathrm{Nu}_{\mathrm{FG}} \mathrm{G}_{\mathrm{G}}$ was used as the average Nusselt number for the heat transfer between the working fluid and the inner wall of the condensing tube.

Equation (18) was employed to calculate the heat transfer coefficient between the heat dissipation surface (aircraft wing) and the surroundings. $\mathrm{u}_{\infty}$ represents the flight speed. The wing was assumed to be cooled through turbulent airflow.

$$
\mathrm{h}=0.0370 \mathrm{k}_{\text {air }}\left(\frac{\mathrm{u}_{\infty}}{v_{\text {air }}}\right)^{0.8} \operatorname{Pr}^{\frac{1}{3}} \mathrm{~L}^{-\frac{1}{5}}
$$

\subsection{Calculation Procedure}

Figure 2 shows a flowchart describing the operation of the control system. First, the accumulator temperature $\mathrm{T}_{\mathrm{acc} 1}$ and heat load conditions at each evaporator were inputted. Unlike an LHP, in the wick-type 2PMPFL, the heat leaked to the accumulator is negligible; therefore, the accumulator is at the surrounding temperature during operation. Assuming that the working fluid in the accumulator and the condensing region operate in a vaporliquid saturation state, the temperature and pressure in the accumulator and the condensing region satisfy the Clausius-Clapeyron equation (Equation (19)). If the pressure difference between the accumulator and the condenser is small, the temperature difference of the working fluid between the accumulator and the condenser is also small; this results in incomplete condensation and ceases the operation. To ensure complete condensation, the accumulator must be heated to increase the temperature of the working fluid in the condenser. Therefore, a sufficient temperature difference between the working fluid and condenser wall is generated for condensation. The calculation results present the wick-type 2PMPFL's operating characteristics when the accumulator is operated at the lowest permitted temperature for completing condensation under each corresponding heat load condition.

$$
\mathrm{P}_{\text {con }}-\mathrm{P}_{\mathrm{acc}}=\left.\frac{\mathrm{dP}}{\mathrm{dT}}\right|_{\text {sat }}\left(\mathrm{T}_{\mathrm{con}}-\mathrm{T}_{\mathrm{acc}}\right)
$$

After inputting the accumulator temperature $\mathrm{T}_{\mathrm{acc} 1}$ and consequently the heat load conditions at each evaporator, the initial value of the pump output, evaporating temperature in the evaporator, and heat leak from the evaporator side to the CC side were set. Next, the mass flow rate in the main and bypass flow paths and the $C C$ temperature $T_{\mathrm{cc} 1}$ were calculated using the initial and input values. Thereafter, the temperature and pressure values in the vapor, condenser, liquid, and bypass lines were sequentially ordered along the flow direction of the working fluid. The accumulator is saturated with vapor-liquid, which allows for the calculation of a second temperature, $\mathrm{T}_{\mathrm{acc} 2}$, $\mathrm{using}$ the saturation vapor curve, provided the pressure value of the accumulator is available. The calculation result for the accumulator's temperature is acquired by adjusting the initial value, $\mathrm{T}_{\text {acc } 1}$, until the difference between $\mathrm{T}_{\mathrm{acc} 1}$ and $\mathrm{T}_{\mathrm{acc} 2}$ is less than $0.1^{\circ} \mathrm{C}$. 


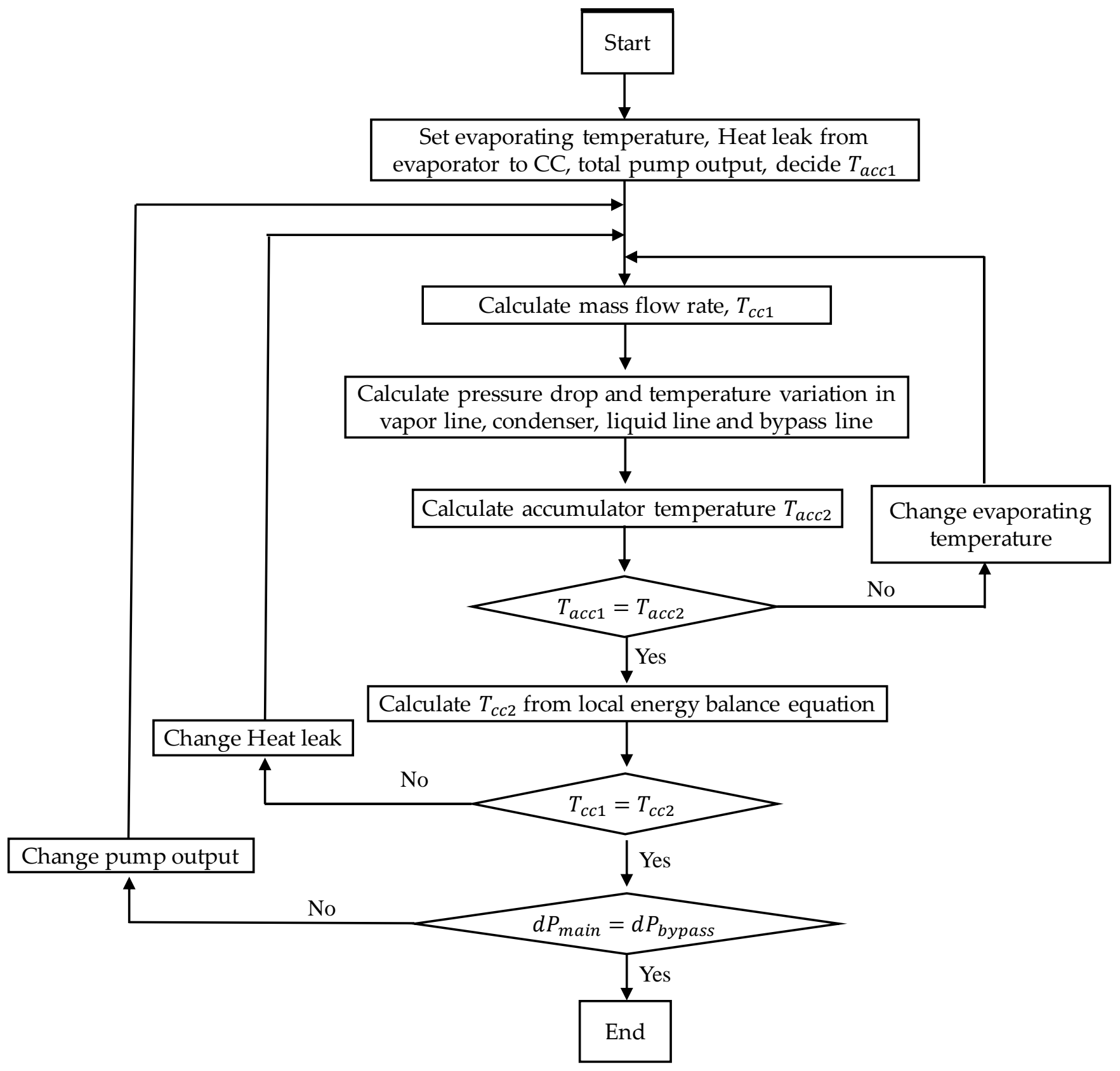

Figure 2. Flow chart of control system operation.

Subsequently, the energy equation for the CC (Equation (5)) is used to calculate another $\mathrm{CC}$ temperature, $\mathrm{T}_{\mathrm{cc} 2}$. The calculation result for the $\mathrm{CC}^{\prime} \mathrm{s}$ temperature $\mathrm{T}_{\mathrm{cc} 2}$ is acquired by following the same steps as those for the accumulator's temperature.

The mass flow rate in the vapor line was calculated using the corresponding heat load condition, and the mass flow rate in the bypass line was calculated using the pump output and the mass flow rate in the vapor line. The optimal output of the pump was calculated using the power consumption and the vapor-liquid separation condition. The conditions for the optimal output are satisfied when only the vapor exists in the vapor line and only liquid exists in the bypass line. The mass flow rate in the main and bypass flow paths should follow the relationship that the pressure drop of the main flow path is equal to the pressure drop of the bypass flow path. In the numerical model, the optimal pump output can be calculated by adjusting the initial value of the pump output until the pressure difference between the main and bypass flow paths is less than $10 \mathrm{~Pa}$. Under optimal operation, the pump consumes the minimum power required, circulates the working fluid, 
and realizes the separation of vapor and liquid in the evaporator. If the pressure drop of the main flow path is greater than that in the bypass flow path, a part of the vapor penetrates the CC and flows through the bypass flow path, resulting in a high operating temperature and a deteriorating operating state. By contrast, if the pressure drop of the bypass flow path is greater, some of the liquid will flow out of the wick with the vapor. If this occurs, the pump consumes more power than required, and the separation of the vapor and liquid flows in the evaporator cannot be realized.

According to Figure 1, assuming that the mass flow rates of the returning liquid to each CC, in the main flow path of each evaporator, and in the bypass flow path of each evaporator are $\dot{\mathrm{m}}_{\mathrm{c} 1}, \dot{\mathrm{m}}_{\mathrm{c} 2}, \dot{\mathrm{m}}_{\mathrm{c} 3}, \dot{\mathrm{m}}_{\mathrm{c} 4} ; \dot{\mathrm{m}}_{\mathrm{a} 1}, \dot{\mathrm{m}}_{\mathrm{a} 2}, \dot{\mathrm{m}}_{\mathrm{a} 3}, \dot{\mathrm{m}}_{\mathrm{a} 4} ;$ and $\dot{\mathrm{m}}_{\mathrm{b} 1}, \dot{\mathrm{m}}_{\mathrm{b} 2}, \dot{\mathrm{m}}_{\mathrm{b} 3}, \dot{\mathrm{m}}_{\mathrm{b} 4}$, respectively, the relation between the mass flow rates in each flow path satisfies Equations (20)-(22), provided all the evaporators are operated under even heat load conditions. Under uneven heat load conditions, assuming that evaporator 1 is heated with the highest heat load and the initial values of the temperature and mass flow rate, the initial value of the evaporating temperature in the other evaporators is adjusted until the difference in the pressure calculation results at point $A$ through the flow paths with $\dot{\mathrm{m}}_{\mathrm{a} 1}, \dot{\mathrm{m}}_{\mathrm{a} 2}, \dot{\mathrm{m}}_{\mathrm{a} 3}$, and $\dot{\mathrm{m}}_{\mathrm{a} 4}$ is less than $10 \mathrm{~Pa}$. Subsequently, the initial value of the mass flow rate is adjusted on each evaporator's bypass line until the difference in the pressure calculation results at point $\mathrm{B}$ through the flow paths with $\dot{\mathrm{m}}_{\mathrm{c} 1} \dot{\mathrm{m}}_{\mathrm{b} 1}, \dot{\mathrm{m}}_{\mathrm{c} 2} \dot{\mathrm{m}}_{\mathrm{b} 2}, \dot{\mathrm{m}}_{\mathrm{c} 3} \dot{\mathrm{m}}_{\mathrm{b} 3}$, and $\dot{\mathrm{m}}_{\mathrm{c} 4} \dot{\mathrm{m}}_{\mathrm{b} 4}$ is less than $10 \mathrm{~Pa}$.

$$
\begin{aligned}
& \dot{\mathrm{m}}_{\mathrm{a} 1}=\dot{\mathrm{m}}_{\mathrm{a} 2}=\dot{\mathrm{m}}_{\mathrm{a} 3}=\dot{\mathrm{m}}_{\mathrm{a} 4} \\
& \dot{\mathrm{m}}_{\mathrm{b} 1}=\dot{\mathrm{m}}_{\mathrm{b} 2}=\dot{\mathrm{m}}_{\mathrm{b} 3}=\dot{\mathrm{m}}_{\mathrm{b} 4} \\
& \dot{\mathrm{m}}_{\mathrm{c} 1}=\dot{\mathrm{m}}_{\mathrm{c} 2}=\dot{\mathrm{m}}_{\mathrm{c} 3}=\dot{\mathrm{m}}_{\mathrm{c} 4}
\end{aligned}
$$

\subsection{Calculation Conditions}

The flow of the working fluid was approximated to be a one-dimensional incompressible viscous flow. Referring to the National Institute of Standards and Technology (NIST) reference fluid properties [46], the thermophysical properties of the working fluid were used in the functions of temperature in the form of a polynomial. Uniform temperature distribution was assumed at the heating surface of the evaporator and the heat dissipation surface of the condenser. The only liquid flow was considered to exist in the CC and bypass flow path.

\section{Calculation Results}

The validation of the numerical model for two types of two-evaporators LHP was conducted at first. When comparing the operating characteristics of two-evaporators LHP with the wick-type 2PMPFL with four evaporators, the only difference is that in the twoevaporators LHP, the separation of vapor and liquid flow is realized in the evaporator as a result of the wick, while in the wick-type 2PMPFL with four evaporators, the vapor and liquid flow cannot be realized unless the optimal pump capacity is attained. Therefore, under the optimal pump capacity condition (i.e., the vapor-liquid separation condition in the wick-type 2PMPFL system's evaporator), the operating characteristics of the twoevaporators LHP and the wick-type 2PMPFL with four evaporators are identical. If the numerical model is validated in the two-evaporators LHP, the validation of the numerical model for wick-type 2PMPFL with four evaporators under the optimal pump capacity condition will also be realized.

Figure 3 presents the comparison between calculation and the experimental results of one LHP with two evaporators (wick material: polytetrafluoroethylene, working fluid: acetone). Figure 4 presents the comparison between the calculations and the experimental results of another LHP with two evaporators (wick material: stainless steel 316L, working fluid: ammonia). The detailed configurations of both the two-evaporators LHPs were described in the references $[47,48]$. In Figures 3 and 4 , the x-axis shows the heat load at each evaporator, while the $y$-axis shows the calculations and the experimental results of each 
evaporator case's steady-state temperature. Since the temperature difference between the calculations and the experimental results was small in both types of two-evaporators LHP, the validation of the numerical model for two-evaporators LHP was realized. Therefore, under the optimal pump capacity condition, the validation of the wick-type 2PMPFL was realized.

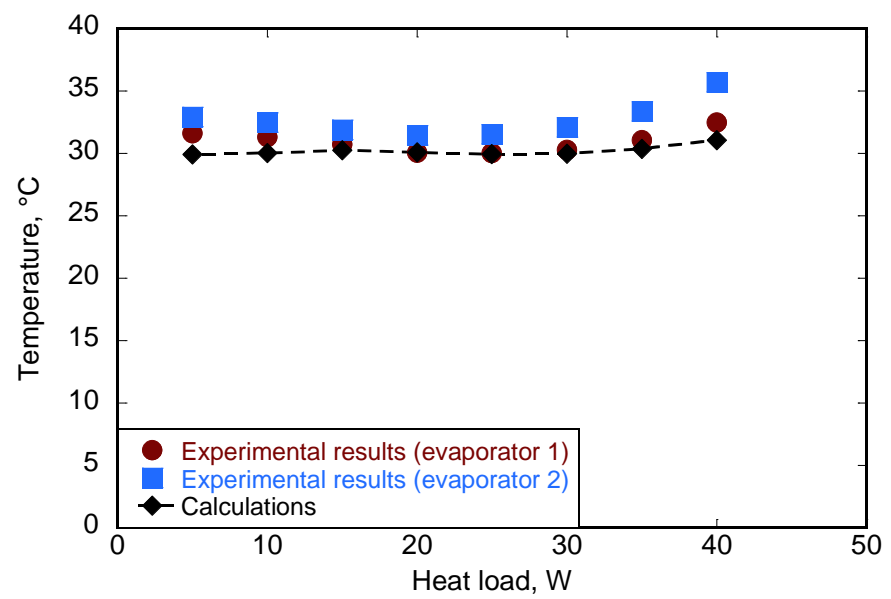

Figure 3. Calculations and experiment results of the two-evaporators type LHP's each evaporator case's temperature according to the reference [47] (wick material: polytetrafluoroethylene, working fluid: acetone).

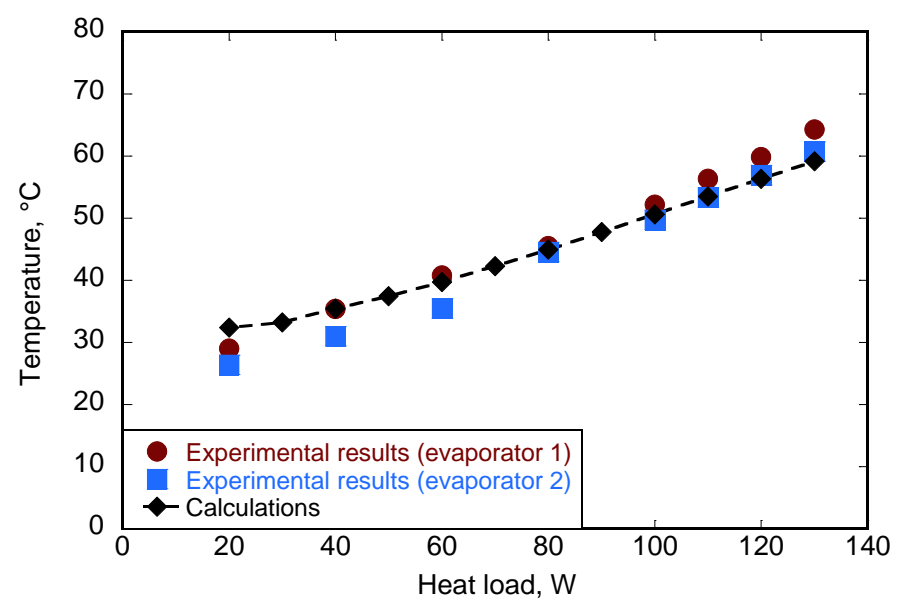

Figure 4. Calculations and experiment results of the two-evaporators type LHP's each evaporator case's temperature according to the reference [48] (wick material: stainless steel 316L, working fluid: ammonia).

The following calculations of the wick-type 2PMPFL with four evaporators were performed under the assumption that the pump operated at its optimal output. The factors investigated were the mass flow rate in each flow path, the minimum operating temperature of the accumulator, and the operating behavior of the evaporators and CCs. Figure 5 shows the calculation results for the evaporator temperature and the lowest accumulator temperature under even heat load conditions. The heat load for each evaporator was increased from $0.3 \mathrm{~kW}$ to $3.6 \mathrm{~kW}$ with an increment of $0.3 \mathrm{~kW}$. The wick-type 2PMPFL operated until the heat loads were increased to $3.6 \mathrm{~kW}$, where the operating temperature of each evaporator was higher than the $80{ }^{\circ} \mathrm{C}$ limit. The wick-type 2PMPFL transferred a total of $13.2 \mathrm{~kW}$ (3.3 kW for each evaporator), which satisfies the design requirement of a total heat transfer capability of $12 \mathrm{~kW}$ (3 kW for each evaporator). 


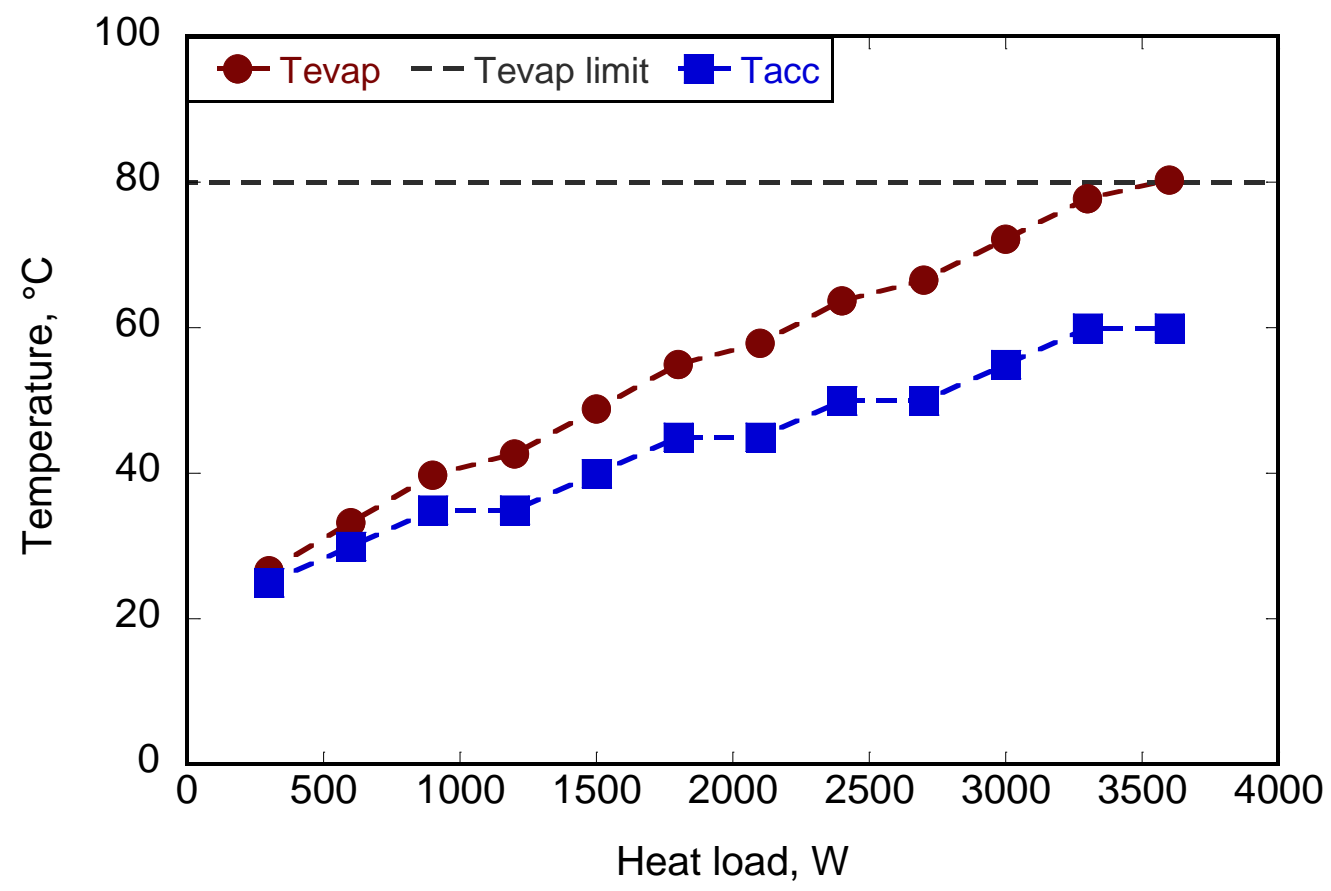

Figure 5. Calculation results of the evaporator temperature and accumulator's lowest temperature under even heat loads conditions.

Following the same load conditions as those in Figures 6 and 7 shows the ratio of the mass flow rate in the main to the bypass flow path, as well as the subcooled length in the condenser. As the four evaporators received the same heat loads, the ratio of the mass flow rate in the main flow path to the mass flow rate in the bypass flow path was the same for each evaporator, as shown in Equation (23). Furthermore, as indicated in Figure 6, the ratio of the mass flow rate in the main flow loop to the mass flow rate in the bypass flow loop increased with the heat loads, whereas the subcooled region length decreased, except in the fluctuating regions. This was attributed to the rough calculation with $5^{\circ} \mathrm{C}$ temperature variations in each step in the accumulator temperature. With a more accurate calculation of the accumulator's temperature (i.e., smaller temperature variations in each step), the fluctuating regions will disappear.

$$
\frac{\dot{\mathrm{m}}_{\mathrm{a} 1}}{\dot{\mathrm{m}}_{\mathrm{b} 1}}=\frac{\dot{\mathrm{m}}_{\mathrm{a} 2}}{\dot{\mathrm{m}}_{\mathrm{b} 2}}=\frac{\dot{\mathrm{m}}_{\mathrm{a} 3}}{\dot{\mathrm{m}}_{\mathrm{b} 3}}=\frac{\dot{\mathrm{m}}_{\mathrm{a} 4}}{\dot{\mathrm{m}}_{\mathrm{b} 4}}
$$

Figure 7 shows the head (Equation (24)) and capacity (Equation (25)) under each corresponding heat load condition when the optimal pump output was realized. The mechanical pump, which satisfies both requirements, will be selected in the future.

$$
\begin{aligned}
\text { Head } & =\frac{\mathrm{dP}_{\text {total }}}{\rho \mathrm{g}} \\
\text { Capacity } & =\frac{60 \dot{\mathrm{m}}}{\rho} \times 1000
\end{aligned}
$$




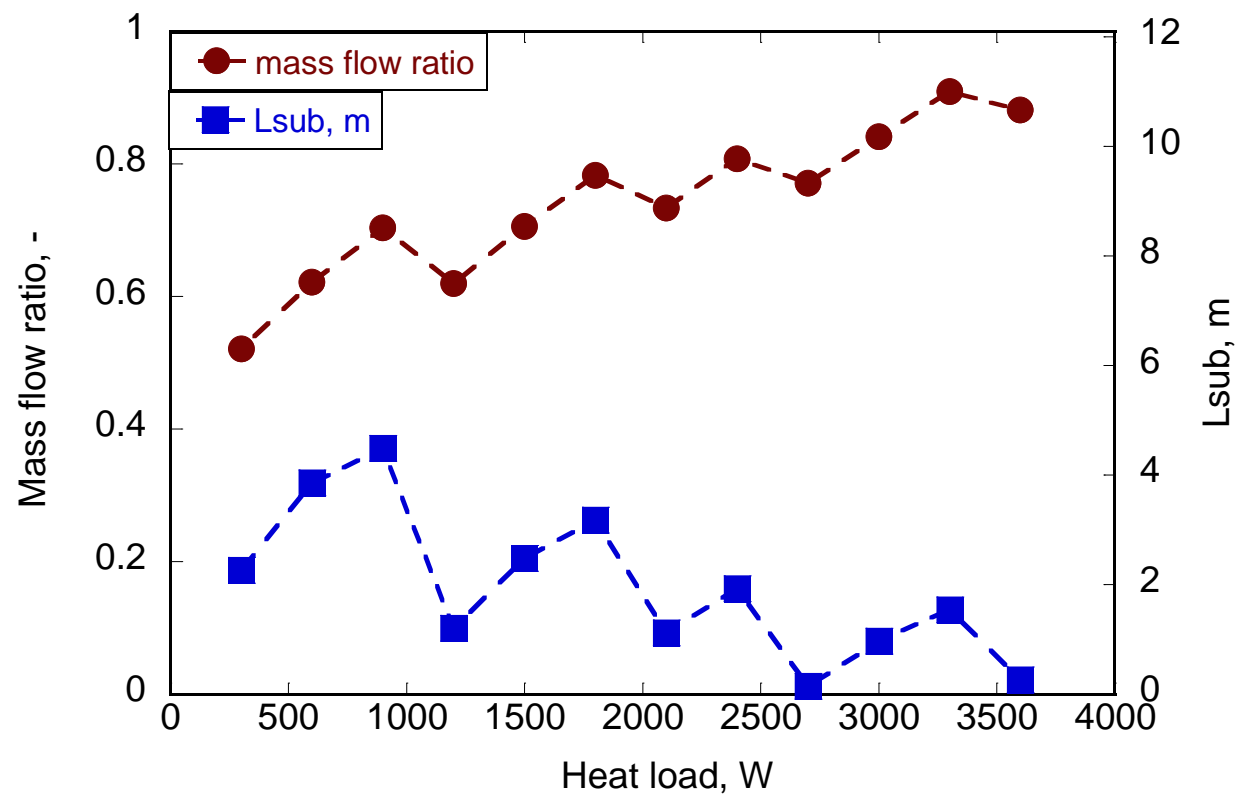

Figure 6. Calculation results of mass flow ratio and subcooled region length under even heat loads conditions.

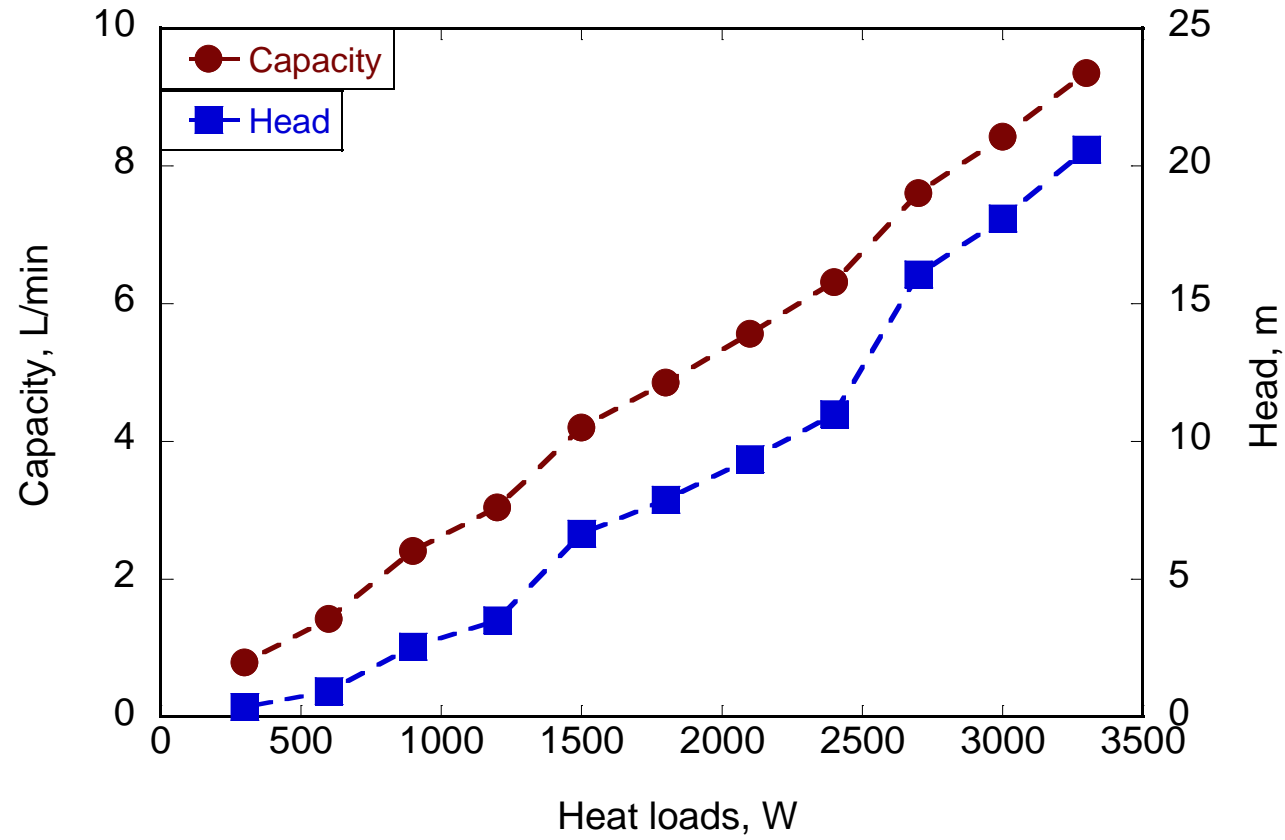

Figure 7. Calculation results for pump capacity and head requirements under even heat loads conditions.

Table 2 shows each evaporator's temperature and the percentage of mass flow rate in each returning liquid line $\left(\mathrm{m}_{\mathrm{c} 1}, \mathrm{~m}_{\mathrm{c} 2}, \mathrm{~m}_{\mathrm{c} 3}, \mathrm{~m}_{\mathrm{c} 4}\right)$, each vapor line $\left(\mathrm{m}_{\mathrm{a} 1}, \mathrm{~m}_{\mathrm{a} 2}, \mathrm{~m}_{\mathrm{a} 3}, \mathrm{~m}_{\mathrm{a} 4}\right)$, and each bypass line $\left(\mathrm{m}_{\mathrm{b} 1}, \mathrm{~m}_{\mathrm{b} 2}, \mathrm{~m}_{\mathrm{b} 3}, \mathrm{~m}_{\mathrm{b} 4}\right)$ under the uneven heat load conditions, where the heat loads were assumed to be $3 \mathrm{~kW}, 2.7 \mathrm{~kW}, 2.4 \mathrm{~kW}$, and $2.1 \mathrm{~kW}$ for evaporators 1, 2, 3, and 4 , respectively. Therefore, temperature control for each evaporator was feasible, even though all the evaporators operated with different heat loads under the optimal pump output conditions. As shown in Table 2, the mass flow rate of the returning liquid CC 1, $\dot{\mathrm{m}}_{\mathrm{c} 1}$, was the highest, contrary to $\dot{\mathrm{m}}_{\mathrm{b} 1}$ in the bypass flow path with the smallest value. 
Table 2. Calculation results of operating temperature and the mass flow rate in each flow path for each evaporator.

\begin{tabular}{cccc}
\hline & Heat Loads $(\mathbf{W})$ & Evaporator Temperature $\left({ }^{\circ} \mathbf{C}\right)$ & Percentage of $\dot{\mathbf{m}}_{\mathbf{c} 1-\mathbf{c} 4}\left(\dot{\mathbf{m}}_{\mathbf{a} 1-\mathbf{a} 4,} \dot{\mathbf{m}}_{\mathbf{b} 1-\mathbf{b} 4}\right)(\mathbf{\%})$ \\
\hline Evaporator 1 & 3000 & 71.3 & $25.6(13.6,12.0)$ \\
\hline Evaporator 2 & 2700 & 70.3 & $25.1(12.2,12.9)$ \\
\hline Evaporator 3 & 2400 & 69.2 & $24.9(10.8,14.1)$ \\
\hline Evaporator 4 & 2100 & 68.2 & $24.4(9.4,15.0)$ \\
\hline
\end{tabular}

\section{Conclusions}

In this paper, to solve the thermal control system of future electric aircraft, a wicktype 2PMPFL system with four evaporators was proposed for cooling the cruise motor of the X-57 electric aircraft. A numerical model was established to predict the operating characteristics of the wick-type 2PMPFL system. For the first time, the pump's optimal output condition based on mass flow rate was investigated, which enabled the selection of an appropriate pump according to the mass flow rate calculated from the heat load conditions. Based on the validation of the numerical model for the two-evaporators LHP, the numerical model for wick-type 2PMPFL with four evaporators under the optimal pump output condition was validated. Under the even heat load conditions, the wick-type 2PMPFL system can transfer $13.2 \mathrm{~kW}$ ( $3.3 \mathrm{~kW}$ for each evaporator) within the temperature upper limit of $80^{\circ} \mathrm{C}$, which satisfied the design goal of $12 \mathrm{~kW}$ ( $3 \mathrm{~kW}$ for each evaporator). Under the uneven heat load conditions with the optimal pump output, it is found that the vapor-liquid separation was realized in four evaporators simultaneously, and the temperature control for each evaporator was feasible. These achievements in the proposal of a wick-type 2PMPFL system will contribute toward establishing an effective future thermal control system for electric aircraft.

Author Contributions: Conceptualization, X.C. and H.N.; methodology, X.C.; software, X.C.; validation, X.C.; formal analysis, X.C.; investigation, X.C. and H.N.; resources, H.N.; data curation, X.C.; writing-original draft preparation, X.C.; writing-review and editing, X.C., K.F. and H.N.; visualization, X.C.; supervision, H.N.; project administration, H.N.; funding acquisition, H.N. All authors have read and agreed to the published version of the manuscript.

Funding: This research received no external funding.

Institutional Review Board Statement: Not applicable.

Informed Consent Statement: Not applicable.

Data Availability Statement: Not applicable.

Conflicts of Interest: The authors declare no conflict of interest.

\section{Nomenclature}

$\mathrm{A}_{\text {wick }} \quad$ Cross-sectional area of the wick, $\left(\mathrm{m}^{2}\right)$

$\mathrm{C}_{\mathrm{F}} \quad$ Parameter for calculation, (-)

$\mathrm{C}_{\mathrm{FG}} \quad$ Parameter for calculation, (-)

$\mathrm{C}_{\text {FG_G }} \quad$ Parameter for calculation, (-)

$\mathrm{C}_{\mathrm{G}} \quad$ Parameter for calculation, (-)

$\mathrm{C}_{\mathrm{p}} \quad$ Specific heat, $\left(\mathrm{J} \cdot \mathrm{kg}^{-1} \cdot \mathrm{K}^{-1}\right)$

$\mathrm{d}_{\text {in }} \quad$ Inner diameter, $(\mathrm{m})$

$\mathrm{dL} \quad$ Distance, $(\mathrm{m})$

$\mathrm{dP} \quad$ Pressure drop, $(\mathrm{Pa})$

$\left(\frac{\mathrm{dP}}{\mathrm{dL}}\right)_{\mathrm{f}, \mathrm{l}} \quad$ Gradient of the pressure drop assuming that the entire working fluid is in the liquid phase, $\left(\mathrm{Pa} \cdot \mathrm{m}^{-1}\right)$ 


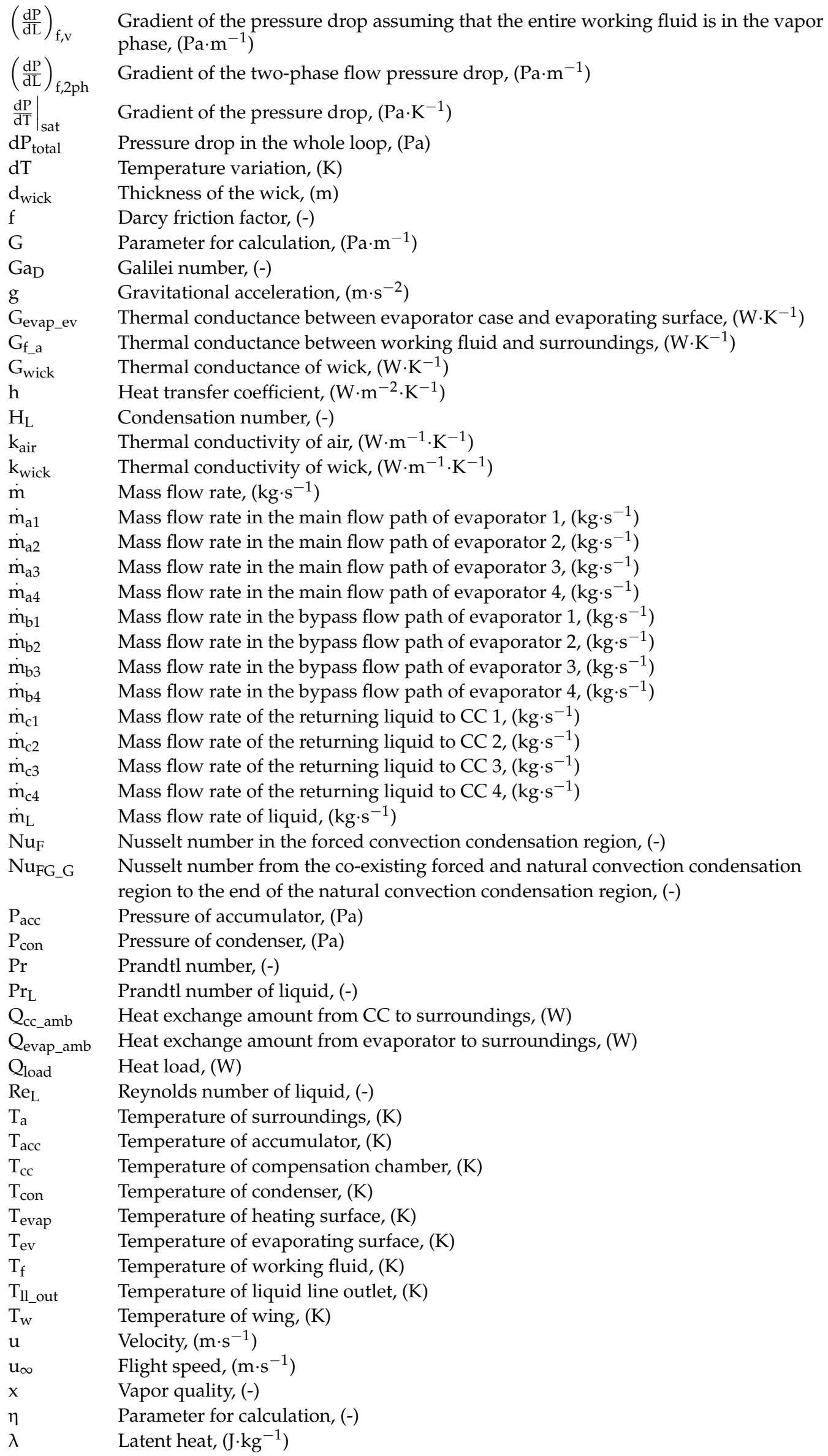




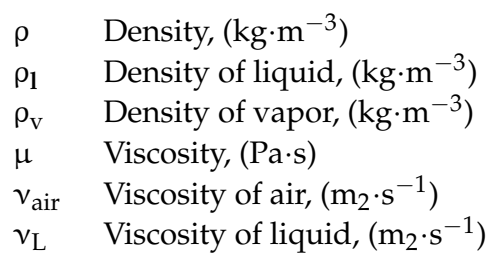

\section{References}

1. Nishizawa, A.; Kobayashi, H.; Iijima, T.; Yamazaki, K.; Okuyama, M.; Tagashira, T.; Hirano, Y.; Yoshimura, A.; Shindo, S.; Okai, K. Flight Demonstration of Electric Propulsion System Technology for Aircraft Application. Aeronaut. Space Sci. Jpn. 2017, 65, 196-200.

2. Bacchini, A.; Cestino, E. Electric VTOL Configurations Comparison. Aerospace 2019, 6, 26. [CrossRef]

3. Montagnani, D.; Tugnoli, M.; Fonte, F.; Zanotti, A.; Syal, M.; Droandi, G. Mid-fidelity analysis of unsteady interactional aerodynamics of complex VTOL configurations. In Proceedings of the 45th European Rotorcraft Forum, Warsaw, Poland, 17-20 September 2019.

4. Hall, D.L.; Chin, J.C.; Anderson, A.D.; Thompson, J.T.; Smith, A.D.; Edwards, R.D.; Duffy, K.P. Development of a Maxwell X-57 high lift motor reference design. In Proceedings of the AIAA Propulsion and Energy 2019 Forum, Indianapolis, IN, USA, 19-22 August 2019.

5. Bradley, M.K.; Droney, C.K. Subsonic Ultra Green Aircraft Research: Phase II-Volume II-Hybrid Electric Design Exploration; NASA/CR-2015-218704/Volume II; Boeing Research and Technology: Huntington Beach, CA, USA, 2019.

6. Kratz, J.L.; Thomas, G.L. Dynamic analysis of the STARC-ABL propulsion system. In Proceedings of the AIAA Propulsion and Energy 2019 Forum, Indianapolis, IN, USA, 19-22 August 2019.

7. Loder, D.C.; Bollman, A.; Armstrong, M.J. Turbo-electric Distributed Aircraft Propulsion: Microgrid Architecture and Evaluation for ECO-150. In Proceedings of the 2018 IEEE Transportation Electrification Conference and Expo, Long Beach, CA, USA, 13-15 June 2018.

8. Berton, J.J.; Haller, W.J. A noise and emissions assessment of the N3-X transport. In Proceedings of the 52nd Aerospace Sciences Meeting, National Harbor, MD, USA, 13-17 January 2014.

9. IATA Technology Roadmap, 4th ed.; International Air Transport Association (IATA): Montreal, Canada, 2013.

10. Freeman, J.; Osterkamp, P.; Green, M.; Gibson, A.; Schiltgen, B. Challenges and Opportunities for Electric Aircraft Thermal Management. Aircr. Eng. Aerosp. Technol. Int. J. 2014, 86, 519-524. [CrossRef]

11. Schiltgen, B.T.; Freeman, J. Aeropropulsive interaction and thermal system integration within the ECO-150: A turboelectric distributed propulsion airliner with conventional electric machines. In Proceedings of the 16th AIAA Aviation Technology, Integration, and Operations Conference, Washington, DC, USA, 13-17 June 2016.

12. Vrable, D.L.; Yerkes, K.L. A Thermal Management Concept for More Electric Aircraft Power System Applications. SAE Trans. Sect. J. Aerosp. 1998, 107, 181-186.

13. Annapragada, S.R.; Macdonald, M.; Sur, A.; Mahmoudi, R.; Lents, C. Hybrid Electric Aircraft Battery Heat Acquisition System. In Proceedings of the 2018 AIAA/IEEE Electric Aircraft Technologies Symposium, Cincinnati, OH, USA, 9-11 July 2018.

14. Deisenroth, D.C.; Ohadi, M. Thermal Management of High-Power Density Electric Motors for Electrification of Aviation and Beyond. Energies 2019, 12, 3594. [CrossRef]

15. Ku, J. Operating characteristics of loop heat pipes. In Proceedings of the 29th International Conference on Environmental Systems, Denver, CO, USA, 12-15 July 1999.

16. Maydanik, Y.F. Loop heat pipes. Appl. Therm. Eng. 2005, 25, 635-657. [CrossRef]

17. Grob, E.; Baker, C.; McCarthy, T. Geoscience laser altimeter system (Glas) loop heat pipes-an eventful first year on orbit. In Proceedings of the 34th International Conference on Environmental Systems, Colorado Springs, CO, USA, $19-22$ July 2004.

18. Fukushima, K.; Nagano, H. New evaporator structure for micro loop heat pipes. Int. J. Heat Mass Transf. 2017, 106, 1327-1334. [CrossRef]

19. Pastukhov, V.G.; Maydanik, Y.F. Active coolers based on copper-water LHPs for desktop PC. Appl. Therm. Eng. 2009, 29, 3140-3143. [CrossRef]

20. Bhandari, P.; Birur, G.; Bame, D.; Mastropietro, A.J.; Miller, J.; Karlmann, P.; Liu, Y.; Anderson, K. Performance of the mechanically pumped fluid loop rover heat rejection system used for thermal control of the Mars science laboratory curiosity rover on the surface of Mars. In Proceedings of the 43rd International Conference on Environmental Systems, Vail, CO, USA, 14-18 July 2013.

21. Daimaru, T.; Furst, B.; Cappucci, S.; Sunada, E.; Birur, G. Development of an evaporator using porous wick structure for a two-phase mechanically pumped fluid loop. In Proceedings of the 49th International Conference On Environmental Systems, Boston, MA, USA, 7-11 July 2019.

22. Kawasaki, H.; Fujii, K. Ground test loop for interfacial behaviors and heat transfer characteristics in boiling two phase flow (JEM-TPF). In Proceedings of the 41st International Conference on Environmental Systems, Portland, OR, USA, 17-21 July 2011.

23. Ohta, H.; Asano, H.; Kawanami, O.; Suzuki, K.; Imai, R.; Shinmoto, Y.; Matsumoto, S.; Kurimoto, T.; Takaoka, H.; Fujii, K.; et al. Development of boiling and two-phase flow experiments on board ISS (Research Objectives and Concept of Experimental Setup). Int. J. Microgravity Sci. Appl. 2016, 33, 330102. 
24. Imai, R.; Suzuki, K.; Kawasaki, H.; Ohta, H.; Shinmoto, Y.; Asano, H.; Kawanami, O.; Fujii, K.; Matsumoto, S.; Kurimoto, T.; et al. Development of Boiling and Two-phase Flow Experiments on Board ISS (Condensation section). Int. J. Microgravity Sci. Appl. 2016, 33, 330103.

25. Gomyo, T.; Asano, H.; Ohta, H.; Shinmoto, Y.; Kawanami, O.; Suzuki, K.; Imai, R.; Oka, T.; Tomobe, T.; Usuku, K.; et al. Development of Boiling and Two-phase Flow Experiments on Board ISS (Void Fraction Characteristics in the Observation Section just at the Downstream of the Heating Section). Int. J. Microgravity Sci. Appl. 2016, 33, 330104.

26. Hirokawa, T.; Yamamoto, D.; Yamamoto, D.; Shinmoto, Y.; Ohta, H.; Asano, H.; Kawanami, O.; Suzuki, K.; Imai, R.; Takayanagi, M.; et al. Development of Boiling and Two-phase Flow Experiments on Board ISS (Investigation on Performance of Ground Model). Int. J. Microgravity Sci. Appl. 2016, 33, 330105.

27. Sawada, K.; Kurimoto, T.; Okamoto, A.; Matsumoto, S.; Takaoka, H.; Kawasaki, H.; Takayanagi, M.; Shinmoto, Y.; Asano, H.; Kawanami, O.; et al. Development of Boiling and Two-phase Flow Experiments on Board ISS (Dissolved Air Effects on Subcooled Flow Boiling Characteristics). Int. J. Microgravity Sci. Appl. 2016, 33, 330106.

28. Okubo, M.; Kawanami, O.; Nakamoto, K.; Asano, H.; Ohta, H.; Shinmoto, Y.; Suzuki, K.; Imai, R.; Matsumoto, S.; Kurimoto, T.; et al. Development of Boiling and Two-phase Flow Experiments on Board ISS (Temperature Data Derivation and Image Analysis of a Transparent Heated Short Tube in the Glass Heated Section). Int. J. Microgravity Sci. Appl. 2016, 33, 330107.

29. Schweizer, N.; Stephan, P.; Schlitt, R. A concept for a miniature, mechanically pumped two-phase cooling loop. In Proceedings of the 38th International Conference On Environmental Systems, San Francisco, CA, USA, 29 June-2 July 2008.

30. Khrustalev, D.; Holman, T.; Baldauff, R. Operational principles of a pump-augmented loop heat pipe with auxiliary evaporators. In Proceedings of the AIAA Propulsion and Energy 2020 Forum, virtual event, 24-28 August 2020.

31. Furukawa, M.; Mimura, K.; Komori, M. Demonstrative in-orbit operations of a pressure-regulated two-phase fluid loop model. In Proceedings of the 7th AIAA/ASME Joint Thermophysics and Heat Transfer Conference, Albuquerque, NM, USA, 15-18 June 1998.

32. Hoang, T.T.; Baldauff, R.W.; Cheung, K.H. Hybrid two-phase mechanical/capillary pumped loop for high-capacity heat transport. In Proceedings of the 37th International Conference On Environmental Systems, Chicago, IL, USA, 9-12 July 2007.

33. Park, C.; Vallury, A.; Zuo, J.; Perez, J.; Rogers, P. Electronics thermal management using advanced hybrid two-phase loop technology. In Proceedings of the 2007 ASME-JSME Thermal Engineering Summer Heat Transfer Conference, Vancouver, Canada, 8-12 July 2007.

34. Crepinsek, M.; Park, C. Effect of Operational Conditions on Cooling Performance of Pump-Assisted Capillary-Driven Two-Phase Loop. J. Thermophys. Heat Transf. 2011, 25, 572-580. [CrossRef]

35. Jiang, C.; Liu, W.; Wang, H.C.; Wang, D.D.; Yang, J.G.; Li, J.Y.; Liu, Z.C. Experimental investigation of pump-assisted capillary phase change loop. Appl. Therm. Eng. 2014, 71, 581-588. [CrossRef]

36. Park, C.; Vallury, A.; Zuo, J. Performance Evaluation of a Pump-Assisted, Capillary Two-Phase Cooling Loop. J. Therm. Sci. Eng. Appl. 2009, 1, 022004. [CrossRef]

37. Crepinsek, M.; Park, C. Experimental analysis of pump-assisted and capillary-driven dual-evaporators two-phase cooling loop. Appl. Therm. Eng. 2012, 38, 133-142. [CrossRef]

38. Wrenn, K.R.; Wolf, D.A. Test Results for a High Power Thermal Management System. AIP Conf. Proc. 2008, 969, $69-85$.

39. Sunada, E.; Bhandari, P.; Carroll, B.; Hendricks, T.; Furst, B.; Kempenaar, J.; Birur, G.; Nagai, H.; Daimaru, T.; Sakamoto, K.; et al. A two-phase mechanically pumped fluid loop for thermal control of deep space science missions. In Proceedings of the 46th International Conference On Environmental Systems, Vienna, Austria, 10-14 July 2016.

40. Sakamoto, K.; Adachi, T.; Daimaru, T.; Nagai, H.; Sunada, E.; Bhandari, P.; Furst, B. Development of Two-Phase Mechanically Pumped Fluid Loop with Large Isothermal Evaporator using Porous Wick Structure. In Proceedings of the 47th International Conference On Environmental Systems, Charleston, SC, USA, 16-20 July 2017.

41. Nagai, H.; Hirata, T.; Fujita, K. Design for large isothermal evaporator mounted on two-phase mechanically pumped fluid loop. In Proceedings of the 50th International Conference On Environmental Systems, Virtual Event, 12-15 July 2021.

42. Falck, R.D.; Chin, J.C.; Schnulo, S.L.; Burt, J.M.; Gray, J.S. Trajectory Optimization of Electric Aircraft Subject to Subsystem Thermal Constraints. In Proceedings of the 18th AIAA/ISSMO Multidisciplinary Analysis and Optimization Conference, Denver, CO, USA, 5-9 June 2017.

43. Bai, L.; Lin, G.; Zhang, H.; Wen, D. Mathematical modeling of steady-state operation of a loop heat pipe. Appl. Therm. Eng. 2009, 29, 2643-2654. [CrossRef]

44. Müller-Steinhagen, H.; Heck, K. A simple friction pressure drop correlation for two-phase flow in pipes. Chem. Eng. Processing Process Intensif. 1986, 20, 297-308. [CrossRef]

45. Fujii, T. Film Condensation Heat Transfer, 1st ed.; Kyushu University Press: Fukuoka, Japan, 2005; pp. 192-196.

46. Lemmon, E.W.; Huber, M.L.; McLinden, M.O. NIST Standard Reference Database 23: Reference Fluid Thermodynamic and Transport Properties-REFPROP, Version 9.1; National Institute of Standards and Technology: Gaithersburg, MD, USA, 2013.

47. Chang, X.; Nagano, H. Mathematical modeling of multiple evaporators/condensers loop heat pipe operation with flow regulator under various operating conditions. J. Therm. Sci. Technol. 2015, 10, JTST0021. [CrossRef]

48. Chang, X.; Nagano, H.; Okazaki, S.; Ogawa, H.; Nagai, H. Operating characteristics of a loop heat pipe with two evaporators and two condensers, experiment result and mathematical model under thermal vacuum condition. In Proceedings of the Fourth International Forum on Heat Transfer, Sendai, Japan, 2-4 November 2016. 